\title{
GEODIVERSIDADE E O ENSINO DE CIÊNCIAS: UMA PROPOSTA PARA A EDUCAÇÃO INFANTIL
}

\section{Geodiversity and Science Teaching: A proposal for Child Education}

\author{
Rosangela Dias de Melo* \\ Carolina Ferreira de Matos Jauris** \\ Jaqueline Pinto Vargas ${ }^{* * *}$ \\ Elenize Rangel Nicoletti ${ }^{* * * *}$
}

\begin{abstract}
Resumo: Esta pesquisa teve como objetivo discutir o tema Geodiversidade por meio de uma sequência de atividades na Educação Infantil, ressaltando a importância da sua inserção ainda nesta etapa de ensino. A escolha da temática deve-se ao local onde as atividades foram implementadas, Caçapava do Sul - RS, intitulada a capital gaúcha da diversidade geológica. Foram desenvolvidas e implementadas 12 atividades em uma turma de Maternal II da EMEI Nilza Torres Dorneles, com 11 alunos entre três e quatro anos de idade, no segundo semestre de 2018. A abordagem metodológica foi qualitativa de cunho documental, através da análise de diferentes registros obtidos durante as intervenções pedagógicas por meio de observações, filmagens, fotografias e desenhos. Os resultados encontrados apontam que a temática contextualizada com a realidade escolar permite aos estudantes desenvolverem a autonomia e a criticidade, fatores essenciais para a construção de sujeitos autônomos e participativos. Ressalta-se que o desenvolvimento de atividades lúdicas, articuladas aos conhecimentos prévios, pode apropriar-se dos saberes científicos colaborando para alfabetização científica desde a tenra idade.
\end{abstract}

Palavras-chave: Ensino de Geociências. Sequência de atividades. Maternal.

Abstract: This research aimed to discuss the Geodiversity theme through a sequence of activities in Early Childhood Education, highlighting the importance of its insertion in this teaching stage. The choice of the theme is due to the place where the activities were implemented, Caçapava do Sul - RS called the geological diversity capital. Twelve activities were developed and implemented at Nilza Torres Dorneles Pre-Kindergarten in a class with 11 three- and four-year-old students, in the second semester of 2018. The methodological approach

\footnotetext{
* Professora da rede Municipal de ensino de Caçapava do Sul. Especialista em Educação Científica e Tecnológica; Licenciada em Pedagogia. rosangeladiaslarissa@hotmail.com

** Professora Adjunta da Universidade Federal do Pampa. Doutora em Química; Graduada em Química e Química Ambiental. carolinamatos@unipampa.edu.br

*** Professora Adjunta da Universidade Federal do Pampa. Doutora em Química; Graduada em Química. Jaquelinevargas@unipampa.edu.br

**** Professora Adjunta da Universidade Federal do Pampa. Doutora em Educação em Ciências; Graduada em Ciências Biológicas.
} 
was qualitative and documentary, through the analysis of different records. They were obtained during the pedagogical interventions through observations, filming, photography, and drawings. Results show that the contextualized theme with the school reality allowed students to develop autonomy and criticality, essential factors for the construction of autonomous and participative subjects. It is noteworthy that the development of playful activities, articulated with previous knowledge, an appropriate scientific knowledge collaborating for scientific literacy from an early age.

Keywords: Teaching geosciences. Sequence of activities. Pre-Kindergarten.

\section{Introdução}

O presente trabalho tem como tema a Geodiversidade e o Ensino de Ciências na Educação Infantil, neste sentido, propõe atividades práticas de caráter lúdico, com base em conceitos geológicos. Objetiva contribuir com o Ensino de Ciências na Educação Infantil e a disseminação da importância da diversidade geográfica para a formação cidadã. Esta proposta surgiu devido a comunidade escolar pertencer a Caçapava do Sul, cidade que possui o título de capital gaúcha da geodiversidade (RIO GRANDE DO SUL, 2015). O município atrai curiosos e pesquisadores de todo o mundo em busca dos sítios geológicos, que possuem valores científicos, culturais, ecológicos e ambientais, bem como uma diversidade de cenários e paisagens.

A partir desse pressuposto, cabe a responsabilidade de abordar este tema ainda na Educação Infantil, pois trata-se do início da vida escolar do aluno, onde ele inicia a socialização fora do ambiente familiar, tendo contato com novos conhecimentos para sua formação múltipla, iniciando a sua educação para a cidadania. Nesse viés, ressalta-se a importância de realizar a articulação entre a Geodiversidade e o Ensino de Ciências, de forma a auxiliar no desenvolvimento de posturas mais dinâmicas para a formação crítica e autônoma dos sujeitos.

Considerando a importância do Ensino de Ciências, propõe-se atividades que vão ao encontro da realidade das crianças, incentivando-as na pesquisa e na descoberta de novos conceitos. Conforme Salles (2007), a ciência deve propor que o aluno faça uma reelaboração de saberes aprimorando o conhecimento de senso comum para o conhecimento científico. Sendo assim, o aluno precisa ser incentivado a buscar explicações mais lógicas realizando discussões, julgamentos coerentes e levantamento de hipóteses. Por meio das metodologias como a experimentação e a resolução de problemas, pode-se desenvolver indivíduos atuantes na sociedade, além de estimular habilidades como a oralidade, dessa forma ampliando o vocabulário dos alunos.

Através do Ensino de Ciências, a criança desenvolve capacidades relacionadas ao saber e as interações com o meio, bem como, o entendimento e a explicação sobre mudanças e fenômenos que ocorrem na sociedade e as transformações do meio ambiente (GOMES e GOMES, 2002). Com as descobertas feitas em aula durante as situações investigativas, as crianças desenvolvem a capacidade de planejar e coordenar suas ideias de forma reflexiva, despertando a curiosidade e o desenvolvimento do pensamento científico.

O Ensino de Ciências contribui com a formação do indivíduo, para que este seja proativo na sociedade, e facilmente adapte-se às suas mudanças. Assim, é imprescindível que o aluno e o professor estejam preparados para tal ação, de modo que o educador deve ser acima de tudo um pesquisador com condições de identificar as concepções prévias dos seus alunos, despertando neles o interesse e a curiosidade pelo ensino, promovendo condições para que ele atue como um ser crítico, pesquisador e analítico (SALLES, 2007). 
Diversos autores apontam que o Ensino de Ciências é importante para a formação do aluno na fase inicial do seu processo de alfabetização (SALLES, 2007; GOMES; GOMES, 2002; PORTO, 2011; BIZZO, 2009). Entretanto, muitas vezes ela ocorre de forma desarticulada do contexto, não contribuindo para uma compreensão sistêmica do mundo pelas crianças. Sendo assim, é necessário, desde os anos iniciais, proporcionar maior contato do indivíduo com saberes científicos, fazendo com que ele se torne mais ativo e participativo durante o processo de construção do conhecimento.

Desse modo, as Ciências e, em especial a Geociências, podem ser abordadas desde a Educação Infantil, estando interligadas, fazendo com que haja uma evolução social dentro e fora do ambiente escolar. Nesse sentido, o presente trabalho tenta demonstrar, através de estratégias lúdicas, como a temática pode ser abordada para crianças do Maternal, articulandose ao Ensino de Ciências. Embora haja na literatura diversos estudos e relatos sobre os temas Geodiversidade, Ensino de Ciências e Educação Infantil, não foram encontradas pesquisas onde tais temas eram trabalhados concomitantemente, o que ressalta o ineditismo da proposta.

\section{O Ensino de Ciências na Educação infantil e a temática Geodiversidade}

O Ensino de Ciências engloba diversos conceitos abstratos, o que muitas vezes dificulta a tarefa do educador no processo de ensino. Entretanto, como ressalta Bizzo (2009) será através dele que o aluno poderá tornar-se um ser humano mais flexível, crítico, reflexivo, aberto a novas descobertas, visando seu crescimento intelectual e social. Para Porto (2011), o conhecimento sobre o Ensino de Ciências para o aluno da Educação Infantil precisa ser focado na ampliação de novas experiências e construção de conhecimentos diversificados. Portanto, torna-se necessário que estes alunos compreendam sobre experimentos que os levem a novas descobertas, bem como ao fazer científico. Além do mais, através do interesse pela pesquisa, o aluno ampliará seus conhecimentos sobre novos conceitos.

Sendo a Educação Infantil a primeira etapa da educação básica, ela necessita um olhar mais amplo e crítico para determinados assuntos, como, por exemplo, a geodiversidade. Será durante esta etapa que se iniciará o desenvolvimento de inúmeras habilidades nas crianças como o senso investigativo e argumentativo. Portanto, faz-se necessária a busca de novas propostas didáticas para o Ensino de Ciências nessa etapa de ensino.

Levar para o cotidiano educacional assuntos relacionados as Geociências, Geologia e Geodiversidade enriquece os processos de ensino e de aprendizagem de maneira extraordinária, pois, a criança tem a oportunidade de conhecer conceitos novos e vivenciá-los em um ambiente natural. Isso possibilita oportunidades de conhecer fenômenos e processos que ocorrem no meio ambiente e, compreender as várias formas de paisagens que existem. Segundo Garcia (2014), o valor educativo que a Geodiversidade possui contempla o entendimento de fatos que ocorreram na reconstrução da história do Planeta, auxiliando nos estudos para melhorar a relação do ser humano com a sociedade e a natureza.

Segundo Xavier, Meneses e Cavalcante (2017), a importância da diversidade geológica para o entendimento dos processos da evolução dinâmica da Terra vem sendo introduzida na sociedade somente a partir dos anos noventa, podendo ser considerada muito recente. Segundo a definição proposta pela Royal Society for Nature Conservation ela "refere-se à variedade de ambientes geológicos, fenômenos e processos geradores de paisagens, rochas, minerais, fósseis, solos e outros depósitos superficiais que constituem a base para a vida na Terra" (BRILHA, 2005, p. 17). Desse modo, o valor educativo torna a abordagem do tema uma sala de aula ao ar livre, permitindo o contato direto para a observação de exemplos concretos, seja, no âmbito 

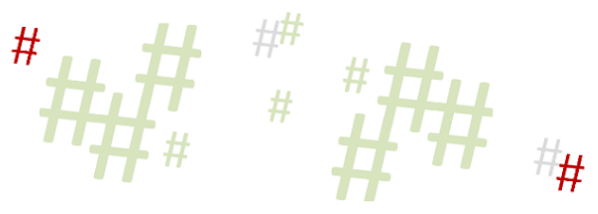

escolar ou com o público em geral. A oportunidade de ter um contato direto com inúmeras paisagens pode inclusive ser aproveitada para enriquecer os conteúdos corriqueiros da sala de aula.

Com a rica diversidade de cenários naturais que existem em meio à natureza e com um potencial desses à disposição, torna-se quase que obrigatório usufruirmos deles para que possamos enriquecer a aprendizagem dos alunos, seja através de vídeos ou fotografias ou se possível através de aulas de campo. Essa metodologia é bastante aceita pelos alunos, pois através delas a teoria aprendida em sala de aula ganha forma e vida. Nesse sentido, as aulas e saídas de campo levam os alunos a uma descoberta do mundo (MEZZOMO; FRICK, 2010). Mas, para que tenhamos um melhor aproveitamento é importante que essas aulas sejam planejadas com cautela e com antecedência, preservando sempre o bem estar de todos os envolvidos (PAZ; FRICK, 2015).

Cabe ao educador tornar-se um mediador entre os conteúdos a serem trabalhados e o potencial concreto que possui a sua volta, compreendendo a importância da Geodiversidade para o meio escolar e seus relacionamentos com a vida das pessoas. Desse modo, é possível abordar sobre as múltiplas relações entre a temática e o meio físico, cultural, desenvolvimento social e econômico. Para que isso ocorra, é necessário que o professor entenda bem sobre a Geodiversidade e seus conceitos, os quais são pouco abordados nos livros didáticos. Compreendendo-os melhor será mais fácil justificar a importância dos mesmos assim como relacioná-los com o cotidiano dos alunos (PAZ; FRICK, 2015).

O Ensino de Ciências pode ser trabalhado desde os primeiros anos de vida, e busca desenvolver atitudes e valores que contribuem para a formação de indivíduos mais eficientes tornando-os cidadãos mais solidários, humanísticos e conscientes. Desta forma, faz-se necessário o cuidado ao introduzir adequadamente os temas cotidianos, e nesse caso a Geologia, na Educação Infantil. Deve-se trabalhar de forma lúdica e pedagógica, pois será nesta etapa que a criança começará a construir sua identidade e autonomia inteirando-se de diferentes situações socioculturais, desenvolvendo, por exemplo, o senso crítico.

Portanto, cabe ao professor pesquisador interagir e introduzir de maneira lúdica e didática temas sobre a Geodiversidade a fim de demonstrar a sua importância para a vida humana e para nosso planeta como um todo. O lúdico é importante tanto nas brincadeiras espontâneas como em atividades planejadas e dirigidas pelo professor, pois em ambas, o aluno desenvolverá diversas habilidades, tanto emocional, psicológica, física, motora e cognitiva. Para Santos (2011) as crianças interagem com os outros e com objetos ao seu redor por meio das brincadeiras. As experiências proporcionadas pela ludicidade desenvolvem a interação do aprender e do ensinar, oportunizando que elas dividam com os demais colegas seus aprendizados. Dessa forma, desenvolver atividades diversificadas para a Educação Infantil pode ser um bom início para a diminuição das lacunas metodológicas encontradas no ensino da Geociências. Como somos privilegiados com uma riquíssima diversidade não precisamos ir muito longe para trabalharmos sobre ela, porque em quase todos os lugares ela está presente, até mesmo em torno da escola. 


\section{Metodologia}

A pesquisa ocorreu na Escola Municipal de Educação Infantil Nilza Torres Dorneles, localizada na cidade de Caçapava do Sul-RS ${ }^{1}$. A instituição comporta atualmente cinquenta e dois alunos entre meninos e meninas de três meses a quatro anos de idade, divididos em quatro turmas distribuídas entre: Berçário, Maternal 1, Maternal 11 e Jardim. A pesquisa ocorreu no segundo semestre de 2018, em uma turma de Maternal II, com onze crianças de três a quatro anos de idade, dentre elas sete meninas e quatro meninos. A professora regente da turma foi quem responsabilizou-se pelas atividades.

\subsection{Abordagem pedagógica}

O projeto foi desenvolvido com base nos assuntos de interesse da turma, bem como, com a preocupação de trabalhar temas referentes a geociências com crianças de três a quatro anos de idade. Através de estudos e leituras em livros, artigos científicos e textos relacionados ao tema do projeto foi possível desenvolver um trabalho que buscou atender às necessidades da turma. $\mathrm{O}$ trabalho desenvolveu atividades com as crianças com o objetivo de promover maior integração com o tema da pesquisa.

As atividades elaboradas foram baseadas na aprendizagem dos alunos a partir de seus conhecimentos prévios e também do seu grau de conhecimento e interesse sobre temas relacionados às Ciências e à geodiversidade. A partir daí, foram elencados os assuntos de interesse da turma. Para a realização do trabalho, diversos recursos didáticos foram utilizados como filmes, jogos, brincadeiras, leituras, dinâmicas, e alguns elementos da geodiversidade como rochas, minerais, fósseis, solos e formas de relevo. Para a interação e produção de novos conhecimentos, desenvolveu-se uma sequência de atividades. Buscou-se assim: estimular o interesse dos pequenos; incentivá-los à pesquisa como forma de se conhecer e descobrir novos conceitos; favorecer a contextualização e a reprodução de histórias; e ainda desenvolver o pensamento reflexivo e crítico.

As atividades realizaram-se em consonância com o cronograma e rotina da instituição, visando propiciar situações onde elas pudessem explorar e observar o meio que as cercam com atitude de curiosidade, percebendo-se como integrante e, ao mesmo tempo, atuante na sua formação. Também se considerou as habilidades e capacidades trazidas pela Base Nacional Comum Curricular (BNCC - BRASIL, 2017), como coordenação motora, orientação, organização temporal e o desenvolvimento da linguagem oral e corporal como forma de comunicação. Foram desenvolvidas ao todo doze atividades, as quais serão detalhadas a seguir no Quadro 1.

\footnotetext{
${ }^{1}$ A primeira autora do trabalho atuava como professora regente da turma investigada, tendo a autorização dos pais para realização das atividades e registros fotográficos. O projeto foi desenvolvido na Especialização em Educação Científica e Tecnológica da Universidade Federal do Pampa, campus Caçapava do Sul, a qual autorizou a pesquisa - aprovada pela Comissão de Curso antes de sua realização.
} 
Quadro 1 - Atividades propostas a turma de Maternal II da EMEI Nilza Torres Dorneles.

\begin{tabular}{|c|c|c|c|c|}
\hline $\mathbf{N}^{\mathbf{o}}$ & Atividades & Materiais & Tempo & Resumo \\
\hline 01 & $\begin{array}{l}\text { A criação do } \\
\text { Universo }\end{array}$ & $\begin{array}{l}\text { Cartazes com desenhos do Big } \\
\text { Bang, dos planetas, da Terra, } \\
\text { dos dinossauros e exemplos } \\
\text { das diferentes formas de vida } \\
\text { no planeta atualmente. }\end{array}$ & $\begin{array}{l}40 \\
\text { minutos }\end{array}$ & $\begin{array}{c}\text { O tema geodiversidade foi apresentado } \\
\text { por meio da história da origem do } \\
\text { universo e da Terra. }\end{array}$ \\
\hline 02 & $\begin{array}{l}\text { Descobrindo a } \\
\text { escavação }\end{array}$ & $\begin{array}{l}\text { Caixa com areia, Fósseis de } \\
\text { argila (insetos, folhas, } \\
\text { animais, pegadas, garras de } \\
\text { dinossauros), pás, pincéis e } \\
\text { palitos. }\end{array}$ & $\begin{array}{l}60 \\
\text { minutos }\end{array}$ & $\begin{array}{l}\text { As crianças brincaram de } \\
\text { paleontólogos, procurando por fósseis } \\
\text { enterrados na areia. Caixas com areia, } \\
\text { contendo fósseis de argila enterrados, } \\
\text { foram distribuídas pelo pátio. Com o } \\
\text { auxílio de pás e pincéis, eles escavaram } \\
\text { na busca pelos materiais. }\end{array}$ \\
\hline 03 & Criando fósseis & $\begin{array}{l}\text { Massa de modelar colorida, } \\
\text { palitos, pás e pincéis. }\end{array}$ & $\begin{array}{l}45 \\
\text { minutos }\end{array}$ & $\begin{array}{c}\text { A turma fez réplicas dos fósseis e de } \\
\text { alguns dinossauros usando massa de } \\
\text { modelar. }\end{array}$ \\
\hline 04 & $\begin{array}{l}\text { Desenho do } \\
\text { Universo }\end{array}$ & $\begin{array}{l}\text { DVD, Folhas de ofício e lápis } \\
\text { colorido. }\end{array}$ & $\begin{array}{l}45 \\
\text { minutos }\end{array}$ & $\begin{array}{l}\text { Após assistirem ao filme 'A era do } \\
\text { gelo' os alunos fizeram desenhos sobre } \\
\text { o big bang e a origem do universo. }\end{array}$ \\
\hline 05 & $\begin{array}{l}\text { Estourando } \\
\text { Balões }\end{array}$ & Balões, fichas e música. & $\begin{array}{l}60 \\
\text { minutos }\end{array}$ & $\begin{array}{c}\text { Essa atividade buscou estimular a } \\
\text { oratória, onde as crianças após estourar } \\
\text { o balão deveriam dizer o seu nome e o } \\
\text { do dinossauro que estava lá dentro } \\
\text { (desenho). }\end{array}$ \\
\hline 06 & $\begin{array}{l}\text { Pintando com a } \\
\text { mão }\end{array}$ & $\begin{array}{l}\text { Tinta têmpera e folhas de } \\
\text { ofício. }\end{array}$ & $\begin{array}{l}60 \\
\text { minutos }\end{array}$ & $\begin{array}{l}\text { Cada criança pintou a ponta do dedo } \\
\text { para fazer o pescoço e a cabeça de um } \\
\text { dinossauro. }\end{array}$ \\
\hline 07 & $\begin{array}{l}\text { Descobrindo a } \\
\text { história do } \\
\text { município }\end{array}$ & $\begin{array}{l}\text { Vídeo, slides, folders, livro, } \\
\text { E.V.A, tesouras e cola. }\end{array}$ & $\begin{array}{l}60 \\
\text { minutos }\end{array}$ & $\begin{array}{c}\text { Após aprenderem sobre a história do } \\
\text { município os alunos representaram uma } \\
\text { preguiça gigante através de colagem em } \\
\text { papel. }\end{array}$ \\
\hline 08 & $\begin{array}{l}\text { Criando o mundo } \\
\text { dos dinossauros }\end{array}$ & $\begin{array}{l}\text { Areia, rochas de vários } \\
\text { tamanhos, cores, formatos e } \\
\text { texturas, galhos, folhas, areia, } \\
\text { terra mais escura, réplicas de } \\
\text { animais como dinossauros, } \\
\text { caixa de papelão e pás }\end{array}$ & $\begin{array}{l}60 \\
\text { minutos }\end{array}$ & $\begin{array}{l}\text { Os alunos realizaram um passeio nas } \\
\text { proximidades da escola para a } \\
\text { observação da paisagem e para a coleta } \\
\text { de alguns materiais como rochas de } \\
\text { vários tamanhos, cores, texturas e } \\
\text { formatos, galhos, folhas, tipos de solo } \\
\text { (arenoso, mais fino, escuro, claro, etc.) } \\
\text { que foram utilizados para a criação de } \\
\text { uma maquete coletiva confeccionado } \\
\text { por eles em uma caixa de papelão. }\end{array}$ \\
\hline
\end{tabular}




\begin{tabular}{|c|c|c|c|c|}
\hline 09 & $\begin{array}{l}\text { Dinossauro } \\
\text { maluco }\end{array}$ & $\begin{array}{l}\text { Figura de dinossauro, tesoura } \\
\text { e giz de cera colorido }\end{array}$ & $\begin{array}{l}60 \\
\text { minutos }\end{array}$ & $\begin{array}{l}\text { Recorte e pintura da figura de um } \\
\text { dinossauro. Os materiais foram } \\
\text { expostos ao final. }\end{array}$ \\
\hline 10 & $\begin{array}{l}\text { Fantoche do } \\
\text { Dinossauro }\end{array}$ & $\begin{array}{l}\text { Material de uso comum, papel } \\
\text { contact, tesouras }\end{array}$ & $\begin{array}{l}45 \\
\text { minutos }\end{array}$ & $\begin{array}{c}\text { Brincadeiras com fantoches de } \\
\text { dinossauros previamente prontos pela } \\
\text { professora. }\end{array}$ \\
\hline 11 & $\begin{array}{l}\text { Confeccionando } \\
\text { o quebra-cabeça } \\
\text { do Dino }\end{array}$ & $\begin{array}{l}\text { Desenho, tesoura, papel } \\
\text { contact e lápis colorido }\end{array}$ & $\begin{array}{l}60 \\
\text { minutos }\end{array}$ & $\begin{array}{c}\text { Atividade de recorte, pintura e } \\
\text { concentração, relacionada a produção } \\
\text { de um jogo de quebra-cabeça. }\end{array}$ \\
\hline 12 & $\begin{array}{l}\text { Exposição dos } \\
\text { Trabalhos }\end{array}$ & $\begin{array}{l}\text { Desenhos, colagens, maquete, } \\
\text { filmes, slides, folders, cartazes } \\
\text { e modelagens }\end{array}$ & $\begin{array}{l}120 \\
\text { minutos }\end{array}$ & $\begin{array}{c}\text { Apresentação de todos os trabalhos } \\
\text { feitos, com a visitação dos outros } \\
\text { alunos da escola, tendo como objetivo } \\
\text { reconhecer a importância da } \\
\text { geodiversidade e a conscientização da } \\
\text { prevenção do meio ambiente. } \\
\text { As crianças foram organizadas em trios } \\
\text { para que pudessem explicar os } \\
\text { conceitos e como tinham realizado a } \\
\text { atividade. }\end{array}$ \\
\hline
\end{tabular}

Fonte: as autoras

\subsection{Metodologia da análise dos resultados}

A metodologia qualitativa, de caráter exploratório, baseou-se na análise dos registros feitos durante as intervenções, tais como desenhos e apresentações dos alunos e questionamentos anotados no diário de bordo da professora. Enquadra-se como uma pesquisa documental (GIL, 2008). Por meio da pesquisa qualitativa reúnem-se dados e informações que não podem ser expressas em números, mas podem incluir, como por exemplo, pinturas, desenhos, fotografias e figuras.

A apresentação dos resultados deste artigo resume-se à análise e coleta dos dados obtidos durante as observações, brincadeiras, diálogos, vídeos, desenhos, atividades lúdicas e do diário de bordo onde registraram-se anotações durante as atividades. Os registros compreenderam as interações das crianças enquanto realizavam as atividades, brincavam, dialogavam, assistiam vídeos e desenhavam. Também, houve o cuidado e anotar as indagações das crianças, as novas descobertas, as investigações e os questionamentos.

\section{Resultados e discussões}

De maneira geral, as crianças demonstraram-se participativas e interessadas durante as atividades, participando ativamente na realização com entusiasmo e determinação. Os alunos as desenvolveram com facilidade, considerando as mesmas fáceis de serem realizadas. Por outro lado, uma minoria apresentou algum nível de dificuldade como, por exemplo, na realização do desenho sobre a origem da Terra. Alguns rabiscaram na folha, mas não conseguiram expressar uma figura clara, talvez por se tratar de um tema relativamente novo para elas. No entanto, a maioria dos alunos manifestou ter compreendido o objetivo proposto. Outro tema novo para eles foram os fósseis, pois nenhum deles tinha noção do termo. Porém, 
quando o assunto foram os dinossauros todos ficaram encantados, pois este é um assunto bem conhecido entre as crianças dessa idade.

Nas atividades sobre a origem da Terra e a importância da geodiversidade, procurou-se explorar os conhecimentos prévios dos alunos sobre os assuntos. Com o auxílio de cartazes e figuras, foi explicado e apresentado acerca do surgimento dos planetas, extinção dos dinossauros e outros animais, a descoberta dos fósseis e sobre a sua utilidade. Também foram discutidos assuntos como as diferentes paisagens, tipos de rochas, água, ar e solo. A criança ao chegar na instituição escolar, traz consigo uma bagagem de conhecimento aprendidos durante o convívio familiar e cultural, pois está inserida na sociedade. Portanto, estes conhecimentos devem ser aproveitados e estimulados pelo professor, o qual tem a tarefa de explorá-los e intensificá-los. Baseando-se neste enfoque, as Diretrizes Curriculares Nacionais para a Educação Infantil (DCNEI) salientam a elaboração de um currículo que atenda essas necessidades das crianças a partir de seus saberes (BRASIL, 2010).

Outro assunto que gerou bastante participação foi a fossilização e extinção dos dinossauros, quando contextualizados com a geodiversidade e sua importância para o desenvolvimento do planeta. Através da atividade de escavação para encontrar os fósseis possibilitou-se a exploração de outros objetos, bem como de outro ambiente. Trabalhar com os alunos em ambientes diferentes da sala de aula serve como um estímulo para realizar a atividade com mais interesse. Puderam expressar-se livremente, discutir com colegas, trocar ideias, procurar soluções para resolver problemas, criar indagações, tirar dúvidas e descobrir através da estimulação e da curiosidade do que era novo para elas. São momentos em que o estudante percebe o seu "estar no mundo", gerando um sentimento de pertencimento a realidade vivida ou imaginada (MEZZOMO; FRICK, 2010). Com esta atividade, estimulou-se as capacidades de relacionamento e convivência com os colegas. Através das brincadeiras é possível suprir suas necessidades de interação e socialização, conhecendo a si mesma e ao outro tendo a oportunidade de conviver com novas culturas através de diferentes experiências, desenvolvendo assim os direitos previstos na BNCC (BRASIL, 2017).

Constatou-se também que as atividades conscientizaram de forma dinâmica e esclarecedora muitas dúvidas presentes, enriquecendo o conhecimento dos alunos e tornandoos seres mais críticos e qualificados para enfrentarem novas descobertas. Dentre o conjunto de atividades desenvolvidas, nove foram selecionadas e são detalhadas a seguir, pois, de acordo com o diário de bordo da professora, foram as que as crianças tiveram um maior envolvimento.

Durante a contação da história (A criação do Universo), ocorreram várias intervenções e questionamentos por parte dos alunos, valorizando o entrosamento entre eles. As crianças demonstraram-se muito interessadas pelo assunto e interrompiam a todo o momento com muita curiosidade.

A segunda atividade (Descobrindo a Escavação), foi planejada para o desenvolvimento da observação, do raciocínio, da curiosidade e do entusiasmo dos estudantes. Destaca-se que essa atividade ocorreu positivamente com a participação de todos. Como mostra a Figura 1A, as crianças realizaram a tarefa de forma dinâmica e lúdica, podendo-se afirmar que aprenderam o conteúdo significativamente com participação coletiva da turma onde os alunos trabalharam de forma amigável e passiva, ajudando uns aos outros.

Cabe destacar que, durante a atividade da escavação, aconteceram questionamentos por parte dos alunos sobre os fósseis encontrados, como por exemplo: 'o que são fósseis?'; 'como eles vieram parar aqui? '; 'tem fósseis aqui na escola?'. Essas perguntas foram respondidas no decorrer do trabalho, por meio de explicações simplificadas e também pela associação da história contada anteriormente. Com a realização desta atividade foi possível expandir a 
compreensão das crianças sobre a temática da diversidade geológica e suas mais variadas formas, como os elementos que a compõe e estão presentes na natureza e também os morros e as rochas.

As crianças observaram através da escavação como se encontra um fóssil e qual a sua importância para o Planeta Terra. Explicou-se que as escavações são realizadas por paleontólogos, que contribuem com a ciência e auxiliam nas pesquisas sobre a história do Universo. Ressaltou-se que os fósseis se formam devido aos fenômenos e mudanças que ocorrem na natureza, salientando-se que várias camadas de solos foram depositadas em cima do fóssil para que ele fique enterrado. Ressaltou-se que somos privilegiados por viver em um município com grande exuberância de paisagens, animais fossilizados e descobertas geológicas como a preguiça gigante (Megatherium Americanum). Por fim, abordou-se a necessidade de cautela na realização da escavação, para que o fóssil não seja danificado ou modificado. Salienta-se que nesta atividade faz-se necessário o acompanhamento de mais pessoas para auxiliar pois, como ocorre no pátio, as crianças se dispersam com muita facilidade.

Figura 1 - Atividades realizadas com as crianças do Maternal. A-Realização da escavação dos fósseis; B- Desenhos feitos pelas crianças sobre o big bang, os dinossauros e os planetas; C-Pintando um dinossauro com a mão.
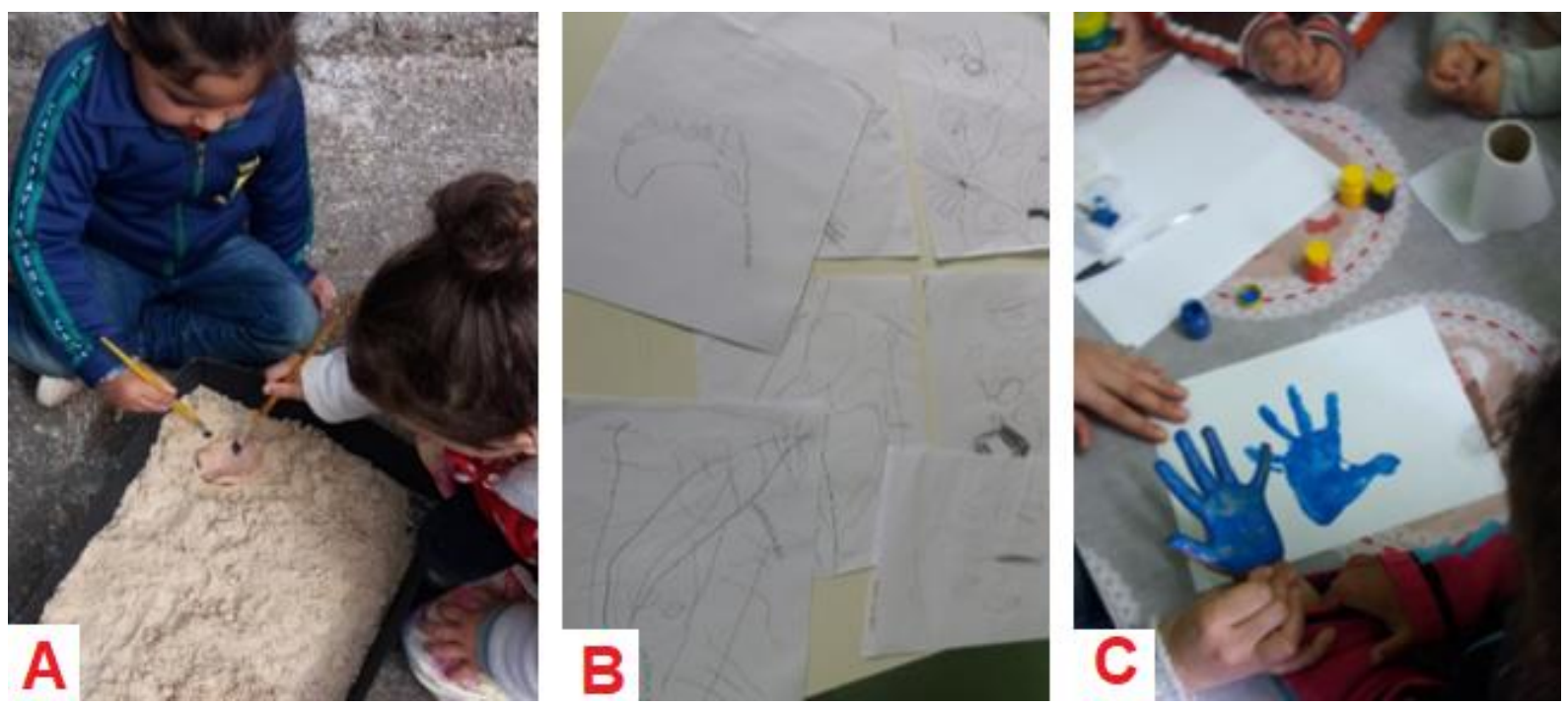

Fonte: autoria própria (2018).

A terceira atividade (Criando Fósseis) buscou estimular a concentração e a criatividade das crianças ao trabalhar com massa de modelar. As tarefas de amassar, amolecer, separar e remontar as peças, prestar atenção aos tamanhos, proporções, formas e texturas auxiliam no desenvolvimento da coordenação motora fina e a mobilidade através da criação de novas formas, sensações e movimentos. Os conceitos trabalhados anteriormente foram significativos, pois alguns deles fizeram paisagens como montanhas e animais, e outros modelaram um dinossauro. Acredita-se que uma das crianças baseou-se na atividade da escavação, pois lá havia um fóssil de uma pegada de dinossauro e a mesma quis representá-lo. A atividade foi desenvolvida pelas crianças com entusiasmo e alegria, pois todos, sem exceção a desenvolveram.

$\mathrm{Na}$ quarta atividade (Desenho do Universo) as crianças apresentaram certa dificuldade em representar o mundo através de um desenho. Pode-se observar que alguns desenhos apresentaram equívocos (Figura 1B), já outros tentaram expressar em seus desenhos uma 
explosão (big bang), indicando que elas associaram ao tema exposto. Através dessa atividade foi possível estimular a atenção, a criatividade, a oralidade e a imaginação a partir da conscientização sobre a importância do Planeta Terra.

Após, realizou-se uma dinâmica (Estourando balões) na qual eles precisavam estourar um balão e dizer o nome do dinossauro cada vez que a música parasse de tocar. Alguns alunos a fizeram de maneira espontânea, natural e divertida, mas outros apresentaram uma certa timidez ao falarem o nome do dinossauro, já outros ficaram como medo de estourar o balão onde o mesmo foi oferecido a outro colega que o furou. Apesar de ser uma atividade que visa proporcionar uma maior interação dos alunos, além de desenvolver concentração, coordenação motora e a habilidade de se movimentar com ritmo, acredita-se que deva ser feita de outra maneira, pois claramente não agradou a todos.

Para a realização da sexta atividade (Pintando com a mão) foi necessário um momento de debates, no qual as crianças explanaram suas ideias e conceitos prévios sobre o tema geodiversidade. Durante a conversa surgiram os dinossauros, bastante apreciados por eles. As crianças assimilaram o surgimento dos animais e sua extinção associando-os ao planeta Terra. Frisou-se que foi através da descoberta de fósseis que se pode imaginar como eram os ambientes, onde esses animais viviam e quais elementos se encontravam presentes na época.

Explicou-se à turma que muitas descobertas sobre a vida destes animais só foram possíveis através da descoberta de fósseis. Partindo-se das conversas, eles optaram pela criação de um dinossauro usando tintas de várias cores (Figura 1C). Ao sentirem a tinta nas suas mãos, as crianças desfrutaram de momentos de realização, desenvolvendo ainda mais a criatividade inerente a elas. Para Barbosa (2015) o envolvimento que as crianças têm por esta prática se justifica pela sua afinidade com o lúdico, a fantasia, a criação e a imaginação. Quando a criança desenha ou pinta ela expõe seu potencial criativo, expressando sensações, sentimentos e pensamentos.

A próxima atividade, representada na Figura 2A (Descobrindo a História do Município) foi desenvolvida pela turma com muita dedicação, interação e responsabilidade. Como ela envolveu o manuseio de tesouras, foi necessário o auxílio de um monitor. O recorte da preguiça gigante em E.V.A. colaborou com o desenvolvimento da motricidade fina, da atenção e da concentração nos pequenos. Observou-se que as crianças nesta faixa etária - dos três aos quatro anos de idade - utilizam a tesoura com alguma precisão e já conseguem fazer alguns cortes curtos em linha reta. Nesta atividade o uso da tesoura pode ser mais explorado acreditando que seja possível começar a praticar novos movimentos tais como as curvas, pois suas habilidades já permitem usar a mesma. 

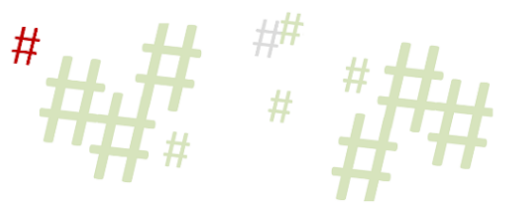

Figura 2 - Continuação da sequência de atividades no Maternal; A- Criança recortando e colando pedaços de E.V.A no desenho da preguiça gigante; B - A turma apresentando a maquete criada por eles; C - Explanação da turma sobre os desenhos e as modelagens feitas sobre geodiversidade para os colegas das demais turmas da escola.
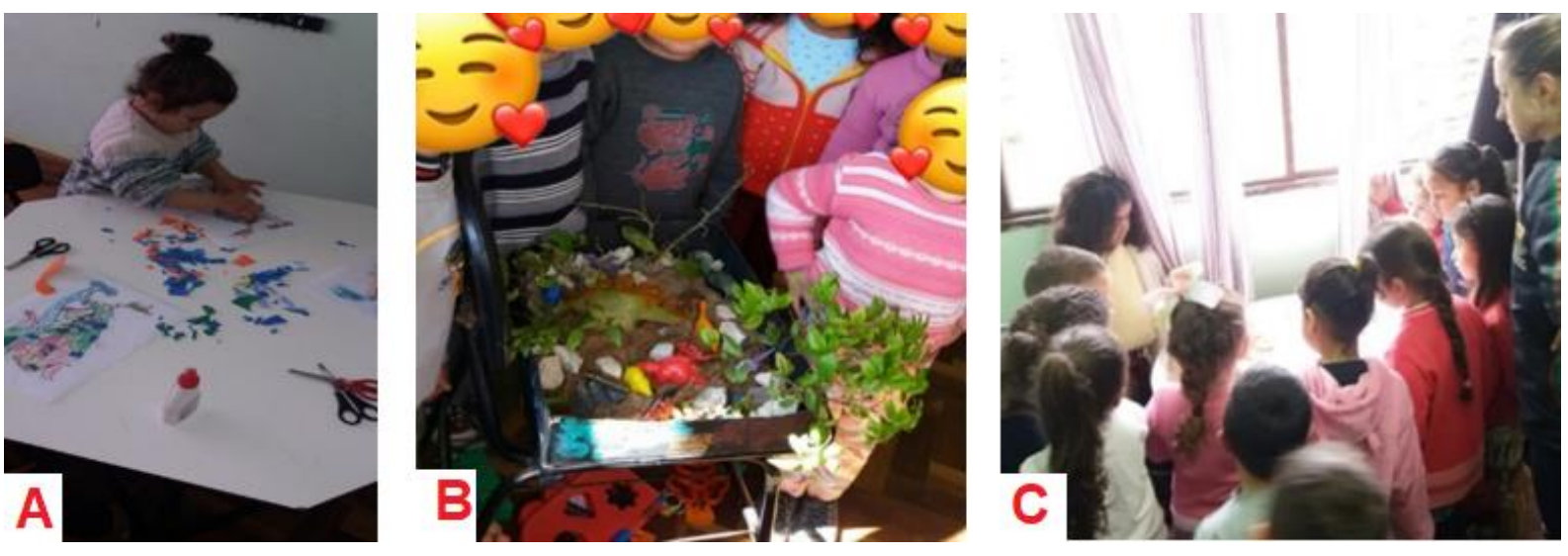

Fonte: autoria própria (2018).

$\mathrm{Na}$ atividade oito ocorreu um passeio e a coleta de materiais (Criando o mundo dos dinossauros), a qual foi sem dúvidas uma das mais prazerosas para as crianças, pois tiveram a oportunidade de sair do ambiente escolar e agir, observar e explorar tudo o que encontravam ao seu redor. Neste momento foi permitido vivenciar situações concretas, onde as crianças selecionaram e compararam diferentes formas e texturas, permitindo uma aprendizagem com significado e principalmente uma melhor compreensão do entorno escolar e do mundo, articulando a teoria à prática.

O trabalho de campo teve grande importância na construção de conhecimentos sobre geodiversidade, pois nesta etapa da Educação Infantil, as crianças constroem seus conceitos baseando-se no real e especialmente no que é visível para eles. Por isso, a importância do professor trabalhar com materiais concretos, porque assim as crianças enriquecem seus conhecimentos prévios e exercitam seus pensamentos. Para isso, o educador precisa prover os direitos previstos na BNCC ao seu alunado. Conforme orienta o documento, o trabalho do professor "é refletir, selecionar, organizar, planejar, mediar e monitorar o conjunto das práticas e interações, garantindo a pluralidade de situações que promovam o desenvolvimento pleno das crianças" (BRASIL, 2017, p. 37).

Ainda, os alunos usaram livremente a imaginação na criação de um mundo dos dinossauros. Utilizando os materiais previamente selecionados, inventaram e acrescentaram ideias e objetos ao seu projeto. Através desta atividade a turma concentrou-se de maneira única, pois todos trabalharam juntos com cooperação, alegria e ajuda mútua no desenvolvimento da atividade (Figura 2B).

Como culminância do projeto ocorreu a socialização das atividades, através da exposição e apresentação dos trabalhos (Figura 2C). As crianças participaram ativamente do início ao final da atividade, organizando os cartazes, mesas e cadeiras para a exposição. Outros professores da escola participaram e puderam analisar as explicações de cada criança. Ainda, puderam observar a compreensão das atividades e, principalmente, ver a empolgação e orgulho que eles sentiram nas suas apresentações. Nesse sentido, concorda-se com Polese (2012, p.95) ao afirmar que "durante a Educação Infantil, a criança passa a ser o sujeito da sua ação, que constrói sua autonomia, sua cidadania, sua educação, sua socialização e seus conhecimentos através da interação". 
Durante as explicações as crianças enfatizaram sobre a importância da geodiversidade, como se encontra no meio ambiente e o que ela representa para o município de Caçapava do Sul. Elas apresentaram os desenhos e as modelagens construídas sobre o surgimento do universo, destacando o surgimento e a extinção dos dinossauros e, também a descoberta da "preguiça gigante". Cada criança falou um pouco sobre os elementos que compõe a geodiversidade como rochas, animais, fósseis e as paisagens nas suas variadas formas. Nesta atividade foi possível avaliar as potencialidades e os desafios no desenvolvimento de uma sequência de atividades sobre geodiversidade na Educação Infantil.

Detectou-se que, embora não apresentassem nenhuma noção sobre geodiversidade, bem como não compreendiam o que era o planeta Terra, entendiam sobre o meio ambiente. Para eles o mundo era o local onde moravam como, por exemplo sua própria casa, como foi citado por um aluno ao esclarecer que morava na casa da avó. Na Educação Infantil, as aprendizagens essenciais compreendem tanto comportamentos, habilidades e conhecimentos, quanto vivências que promovem aprendizagem e desenvolvimento nos diversos campos de experiências, sempre tomando as interações e a brincadeira como eixos estruturantes (BRASIL, 2017).

\section{Considerações finais}

No âmbito da Educação Infantil, constatou-se a necessidade de se trabalhar temas relacionados a Geodiversidade associados ao Ensino de Ciências pois, os mesmos são direcionados para o desenvolvimento de hábitos relacionados à preservação e respeito ao meio ambiente e seres vivos.

As atividades desenvolvidas neste trabalho foram interessantes e estimuladoras ao promoverem situações desafiadoras paras as crianças. Desse modo, além de ensinarem o conteúdo, também proporcionaram aos alunos oportunidades de expressarem-se como agentes ativos e construtores de seus saberes. Sendo desenvolvidas por meio de teorias e práticas, bem como brincadeiras, jogos e atividades lúdicas, oportunizaram que as crianças sentissem entusiasmo no que estavam realizando. Ainda, o conteúdo foi exposto dentro da realidade da turma e das possibilidades cognitivas e peculiares dessa faixa etária.

Percebe-se a necessidade de se trabalhar a diversidade geológica desde as primeiras etapas da Educação Básica, apresentando para as crianças a riqueza que existe no planeta, conscientizando-os sobre a sua importância e a preservação do meio em que vivem. Ressaltase que o desenvolvimento de atividades lúdicas, articuladas aos conhecimentos prévios, auxiliaram na apropriação de saberes científicos colaborando para alfabetização científica desde a tenra idade. Cabe destacar a importância do professor da educação infantil ser também um professor pesquisador, articulando novos conhecimentos aos saberes prévios dos alunos. Nesse viés, pensar nessa perspectiva ainda durante a formação inicial apresenta-se como uma possibilidade de efetivá-la na prática, para que os educadores possam incentivar a autonomia e criticidade desde a Educação Infantil, através da valorização do contexto social e ambiental entre os educandos.

\section{Referências}

BARBOSA, Poliana Priscila Sousa. O ensino de Artes Visuais na Educação Infantil: a prática de leitura e apreciação de obras artísticas. 2015. Monografia (Especialização em Artes) - Escola de Belas Artes, Universidade Federal de Minas Gerais, Belo Horizonte, 2015. 
BIZZO, Nélio. Ciências: fácil ou difícil. 1. ed. São Paulo: Biruta, 2009.

BRASIL. Base Nacional Comum Curricular. Ministério da Educação. Secretaria de Educação Básica. Brasília: MEC/SEB, 2017.

BRASIL. Diretrizes Curriculares Nacionais para a Educação Infantil. Ministério da Educação. Secretaria de Educação Básica. Brasília: MEC/SEB, 2010.

BRILHA, José. Patrimônio Geológico e Geoconservação: a conservação da natureza na sua vertente geológica. Braga: Palimage Editores, 2005.

GARCIA, Taís da Silva. Da Geodiversidade ao Geoturismo: valorização e divulgação do geopatrimônio de Caçapava do Sul, RS, Brasil. 2014. Dissertação (Mestrado em Geografia) Programa de Pós-Graduação em Geografia, Universidade Federal de Santa Maria, Santa Maria, 2014.

GIL, Antonio Carlos. Como elaborar projetos de pesquisa. 4. ed. São Paulo: Atlas, 2008.

GOMES, Carlos; GOMES, Sílvia. Didática para o ensino de Ciências. Curitiba: IESDE, 2002.

MEZZOMO, Maristela Denise Moresco; FRICK, Elaine de Cacia de Lima. Projeto expedições geográficas na Serra do Mar: teoria e prática do ensino de geografia. In: XVI ENCONTRO NACIONAL DOS GEÓGRAFOS, 2010, Porto Alegre. Anais [...]. Porto Alegre: UFRGS, 2010.

PAZ, Otacílio Lopes de Souza da Paz; FRICK, Elaine de Cacia de Lima. Geodiversidade e Geoconservação: possibilidades no âmbito da educação ambiental dentro e fora de sala de aula. In: VII ENCONTRO NACIONAL DE ENSINO DE GEOGRAFIA, 2015, Catalão. Anais [...]. Catalão: UFG, 2015.

POLESE, Nathalia Cunha. Aprendizagem Infantil através do construtivismo: ensinar e aprender. Revista Espaço Acadêmico, Maringá, v. XII, n.134, p. 89-96, jul. 2012.

PORTO, Franciélli Maciel Rodrigues. Ensino de ciências na Educação Infantil. 2011. Monografia (Especialização em Ensino de Ciências) - Universidade Tecnológica Federal do Paraná, Toledo, 2011.

RIO GRANDE DO SUL. Lei $n^{\circ} 14.708$, de 15 de julho de 2015. Declara o município de Caçapava do Sul "Capital Gaúcha da Geodiversidade". Diário Oficial do Estado: Porto Alegre, Rio Grande do Sul, Edição Única, jul. 2015.

SALLES, Gilsani Dalzoto. Metodologia do Ensino de Ciências Biológicas e da Natureza. Curitiba: IBPEX, 2007.

SANTOS, Santa Marli Pires dos Santos. O brincar na escola: metodologia lúdica-vivencial, coletâneas de jogos, brinquedos e dinâmicas. 2. ed. Petrópolis: Vozes, 2011. 
XAVIER, Laysla da Silva.; MENESES, Leonardo Figueiredo de; CAVALCANTE, Márcio Balbino. Ensinando geodiversidade a partir de jogos didáticos. Revista de Ensino de Geografia, Uberlândia, v. 8, n. 15, p. 157-182, jul./dez. 2017.

Recebido em outubro de 2019.

Aprovado em maio de 2020. 